\title{
Development, reliability and use of a food environment assessment tool in supermarkets of four neighbourhoods in Montréal, Canada
}

\author{
Élise Jalbert-Arsenault, DtP (1); Éric Robitaille, PhD (1,2); Marie-Claude Paquette, PhD (1,2)
}

This article has been peer reviewed.

\begin{abstract}
Introduction: The food environment is a promising arena in which to influence people's dietary habits. This study aimed to develop a comprehensive food environment assessment tool for businesses and characterize the food environment of a low-tomedium income area of Montréal, Canada.

Methods: We developed a tool, Mesure de l'environnement alimentaire du consommateur dans les supermarchés (MEAC-S), and tested it for reliability. We used the MEAC-S to assess the consumer food environment of 17 supermarkets in four neighbourhoods of Montréal. We measured the shelf length, variety, price, display counts and in-store positions of fruits and vegetables (FV) and ultra-processed food products (UPFPs). We also assessed fresh FV for quality. Store size was estimated using the total measured shelf length for all food categories. We conducted Spearman correlations between these indicators of the food environment.
\end{abstract}

Results: Reliability analyses revealed satisfactory results for most indicators. Characterization of the food environment revealed high variability in shelf length, variety and price of FV between supermarkets and suggested a disproportionate promotion of UPFPs. Display counts of UPFPs outside their normal display location ranged from 7 to 26 , and they occupied 8 to 33 strategic in-store positions, whereas the number of display counts of fresh FV outside their normal display location exceeded 1 in only 2 of the 17 stores surveyed, and they occupied a maximum of 2 strategic in-store positions per supermarket. Price of UPFPs was inversely associated with their prominence $(p<.005)$ and promotion $(p<.003)$. Store size was associated with display counts and strategic in-store positioning of UPFPs $(p<.001)$, but not FV, and was inversely associated with the price of soft drinks $(p<.003)$.

Conclusion: This study illustrates the variability of the food environment between supermarkets and underscores the importance of measuring in-store characteristics to adequately picture the consumer food environment.

Keywords: nutrition, food environment, consumer food environment, fruits and vegetables, food processing, food marketing, obesity, ultra-processed food products

\section{Introduction}

More than half of Canadian adults are overweight $(36.8 \%)$ or obese $(25.1 \%){ }^{1}$ This represents a significant social and financial burden for the country, with up to $12 \%$ of total health expenditures in Canada estimated to be attributable to obesity. ${ }^{2}$ In Quebec alone, the annual cost of excess weight has been estimated at 3 billion dollars. ${ }^{3}$ Meanwhile, eating behaviours, which are considered one of the main determinants of body weight and a modifiable risk factor for the development of many noncommunicable diseases, ${ }^{4}$ are not optimal in Quebec. The mean consumption of fruits and vegetables (FV) in the adult population is under
Highlights

- The MEAC-S tool was designed to assess and monitor the consumer food environment in Montréal, Canada, and has shown robust interrater reliability.

- The availability and price of fruits and vegetables vary greatly among supermarkets.

- Ultra-processed food products, unlike fruits and vegetables, are highly and disproportionately promoted inside supermarkets, their promotion increasing with store size.

- When assessing the community food environment, food stores cannot be dichotomized into healthy versus unhealthy, as this does not comprehensively capture the food environment to which consumers are exposed.

five portions per day. ${ }^{5} \mathrm{~A}$ recent analysis of the data for Quebec in the Canadian Community Health Survey, Cycle 2.2, Nutrition (2004), have also reported that ultra-processed food products (UPFPs) represent almost half of calories consumed $(47 \%)$ in the province. ${ }^{6}$

The food environment has been shown to influence food choices and dietary patterns. ${ }^{7}$ Community (accessibility of different types of food stores) and consumer (what is available inside food stores) food environments have been associated with FV consumption, ${ }^{8-13}$ diet quality, $, 111,14-18$ and weight. ${ }^{19-25}$ In Canada, the current food environment provides cheap, readily available, and massively marketed highenergy-density foods and UPFPs. ${ }^{26}$ In such 
a skewed food environment, nutrition education is most likely insufficient to improve the population's eating habits. ${ }^{27,28}$ To start curbing the rise in the prevalence of obesity, changes in the food environment are essential to make the healthy choice the easy choice.

The food environment in Canada and in Quebec is currently not well documented. This scarcity of data impedes the ability to orient, develop and implement interventions and policies that would make it conducive to healthy eating. ${ }^{29} \mathrm{~A}$ recent review by Minaker and colleagues ${ }^{30}$ particularly highlights the lack of research on the consumer food environment in Canada, with only one paper that used measures of the consumer food environment to study the association between food environment and health outcomes. While store proximity and availability in one's neighbourhood have been linked with diet quality, studies have reported inconsistent results, ${ }^{31}$ suggesting that physical accessibility alone might not be sufficient to explain dietary habits. The availability and affordability of the foods within those stores may be contributing to the association between food store access and food store choice, eating behaviours and health outcomes..$^{32,33}$

More than 30 different food environment assessment tools have been identified. ${ }^{34}$ The two most frequently used tools are the Nutrition Environment Measures Survey in Stores (NEMS-S) ${ }^{35}$ and the USDA Thrifty Food Plan. ${ }^{36}$ These tools describe the availability and price of a variety of food products. The NEMS-S also assesses produce quality. Neither of them, nor most other food environment assessment tools, ${ }^{34}$ describe food promotion or the prominence of food categories inside food stores, despite the influence of these factors on food-purchasing decisions. ${ }^{37-40}$

The objectives of this study were to (1) develop a food store survey that incorporates the components of the consumer food environment as defined in the Model of Community Nutrition Environments developed by Glanz and colleagues, including promotion and placement ${ }^{7}$; and (2) characterize the consumer food environment of a low-to-medium income area (4 neighbourhoods) in the southeastern part of Montréal.

\section{Methods}

\section{Tool development}

The Mesure de l'environnement alimentaire du consommateur dans les supermarchés (MEAC-S) was developed to assess the consumer food environment inside supermarkets.

\section{Food categories}

The MEAC-S includes two foods categories: those that have been documented to be consumed in insufficient quantities (FV category) and those that have been documented to be consumed in too large quantities (UPFPs category) according to recommendations in Canada's Food Guide. ${ }^{5,6}$ The FV category includes fresh, frozen, canned and ready-to-eat FV. The UPFPs category, defined as food products formulated from industrial ingredients and containing little or no whole foods, ${ }^{41}$ includes chips, soft drinks, frozen entrees and confectioneries. These foods were chosen because they accounted for $11 \%$ of total supermarket sales in the province in 2013 to $2014 .^{42}$

Pilot testing revealed that confectioneries were available in multiple locations within the store and often shared shelves with other food products. This placement of confectioneries precluded reliable assessment of variety and shelf length for these products. Confectioneries were thus only assessed for availability in strategic instore positioning.

\section{Key indicators}

The MEAC-S assessed availability, affordability, prominence and promotion for both food categories inside supermarkets. Indicators included in the tool are listed and defined below.

1. Availability of food items was operationalized using three indicators: the variety of items in each food category, the shelf length they occupy in the supermarket and the quality of produce.

Variety was calculated by counting every available item per food category, including different sales formats, brands, flavours and types. For example, all available varieties of the same kind of fruit or vegetable were counted separately.

Shelf length was calculated using a steplength method. ${ }^{43}$ The auditor walked in front of every shelf of food included in the tool while counting her steps, which were previously calibrated. In order to measure the accessibility of food for shoppers, audits were taken from every aisle, around island displays and near the cash registers. When a food category was available in multiple locations inside a store, the measurements for all locations were summed to obtain the total shelf length for that food category. Shelves' depth and height were not measured nor accounted for. The total shelf length measured for all food groups was summed to create a proxy of store size.

Quality of produce was evaluated on a three-point scale, from -1 to 1 . It was audited separately for fruits and vegetables and was based on the auditor's evaluation of freshness, according to their appearance, smell and ripeness level. Full criteria for freshness evaluation are provided in the MEAC-S user guide (available from the authors upon request, in French only).

2. Affordability of food was evaluated through the price per portion for FV, price per $100 \mathrm{~g}$ for chips and frozen entrees and price per 2 L for soft drinks. Promotion prices were not considered.

The price per portion for fruits and vegetables was calculated using, respectively, the mean price for one portion of apple, banana, strawberry and orange, and the mean price for one portion of tomato, carrot, lettuce and cucumber. Canada's Food Guide served as a reference for portion size. When more than one kind of these fruit or vegetable was available (e.g. 17 kinds of apple), the lowest regular price was selected.

The prices per $100 \mathrm{~g}$ of chips and frozen entrees and per $2 \mathrm{~L}$ of soft drinks were audited for the lowest-priced product in each store, usually the private label brand. The auditors also recorded prices of standard products that were shown to be available in every store during pilot testing. The standard product for chips was the $180 \mathrm{~g}$ bag of Lay's Original chips and the standard product for frozen entrees was the $286 \mathrm{~g}$ Stouffer's lasagna. The $2 \mathrm{~L}$ bottle of Coke was the standard product for soft drinks.

3. Indicators of prominence were developed to describe the simultaneous exposure 
to healthy and unhealthy food products. These include the "ratio of variety" and the "ratio of shelf length" of FV to UPFPs. The ratio of variety was calculated by dividing the number of products available in the FV category by the number of UPFPs available. The ratio of shelf length was obtained by dividing the total FV shelf length by the total UPFPs shelf length.

4. Promotion of food items was operationalized using two indicators: display counts and strategic in-store positioning of FV, chips, soft drinks and confectioneries. Display counts represent the number of times food products were found outside their principal point of sale in the store (e.g. chips are available in many other locations inside a store other than the chip aisle). Strategic in-store positions are the end of aisles, areas near the cash registers and ready-to-eat displays. The auditors noted the number of these positions occupied by FV, chips, soft drinks and confectioneries.

We conducted a pilot study in five food stores, and adjusted the MEAC-S to facilitate data collection. The final form is presented in Figure 1. The complete user guide is available (in French only) upon request to the corresponding author.

\section{Data collection}

The study took place in four low-tomedium income neighbourhoods in the southeastern part of Montréal, Canada. These neighbourhoods are divided into eight Forward Sortation Areas (FSAs). The first three characters of the postal code identify the FSA. We evaluated every supermarket in these FSAs.

We selected supermarkets using a Google map search. The FSA was entered as primary term and the terms "supermarket" or "grocery store" were entered in the local search engine. We found a total of 57 food stores, of which 18 were supermarkets. In order to ensure that every supermarket was visited, we systematically tracked food stores by going through every major street in the four neighbourhoods. Two stores were not eligible for auditing as one was closed permanently and another was a convenience store. One supermarket was also added to the list, for a total of 17 supermarkets, as illustrated in Figure 2.
Data were collected between May and July 2015 to avoid seasonal influences on FV availability, price and prominence.

We did not seek permission from store managers to assess the food environment inside their supermarket. Therefore, subtlety was a key component of the data collection. The MEAC-S form was printed and folded like a grocery shopping list and the auditor bought food items in every store visited to avoid unwanted attention. No intervention from store managers or employees compromised data collection.

\section{Interrater and test-retest reliability}

In November 2015, five months after the first assessment, two auditors reassessed six stores to evaluate the MEAC-S for interrater and test-retest reliability.

\section{Statistical analysis}

We calculated intraclass correlation coefficients (ICCs) with a two-way random ANOVA model assessing for absolute agreement to evaluate the MEAC-S for interrater and test-retest reliability.

We conducted Spearman correlations between price and prominence indicators, and between store size and all other food environment indicators in supermarkets.

All statistical analyses were performed in SPSS Statistics version 19.0 (IBM Corp., Armonk, NY, USA). A $p$-value inferior to .05 was considered significant.

\section{Results}

All supermarkets included in the study are chain supermarkets, with estimated annual chain sales exceeding $\$ 150$ million. ${ }^{44}$

Audits lasted on average 56 minutes (3275 minutes). We assessed interrater and test-retest reliability using the ICC coefficient for each indicator. An ICC coefficient above 0.75 indicates excellent agreement and an ICC coefficient between 0.40 and 0.75 indicates medium-to-good agreement. ${ }^{45}$

All indicators had an ICC coefficient above 0.85 for interrater reliability, suggesting excellent agreement between auditors. The ICC coefficients for test-retest reliability were lower. ICC coefficients below 0.75 were found for indicators of display counts (0.43) and strategic in-store positioning (0.53) and coefficients were mostly invalid for indicators of price due to within-group to between-group variance (Table 1).

\section{Consumer food environment}

Overall availability, affordability, prominence and promotion of food items per supermarket are described in Table 2.

Availability of food items differed greatly among supermarkets, as illustrated by the variability in variety and shelf length indicators. We calculated variety and shelf length ratios for each store. Ratios above 1.0 indicate greater presence of $\mathrm{FV}$, whereas ratios under 1.0 indicate a greater presence of UPFPs. Two supermarkets had variety ratios inferior to 1.0 and five supermarkets had shelf length ratios inferior to 1.0 .

Price per portion of vegetable varied more than twofold and price per portion of fruit more than threefold from one supermarket to another.

Quality of FV did not differ significantly among supermarkets; most of them offered FV of the highest quality.

Display counts and strategic in-store positioning for UPFPs greatly outnumbered those for FV. Nine supermarkets did not have display counts for FV outside their normal display location or strategic instore positioning for $\mathrm{FV}$, and of the stores that did, 6 out of 8 were for canned FV. In comparison, all stores had at least 7 additional display counts and 8 strategic positions occupied by UPFPs.

\section{Price and prominence of ultra-processed food products}

Results showed that the price of UPFPs such as chips and soft drinks was inversely associated with their availability, prominence and promotion in the supermarket (Table 3 ). This association was not seen for FV (data not shown).

\section{Consumer food environment indicators and supermarket size}

Because supermarket size could account for some of the results, we conducted Spearman correlations between the store size proxy and indicators of the consumer food environment, excluding shelf length measurements (Table 4). 
FIGURE 1

MEAC-S measurement form

Store:

Evaluation date:
Address:

Duration:

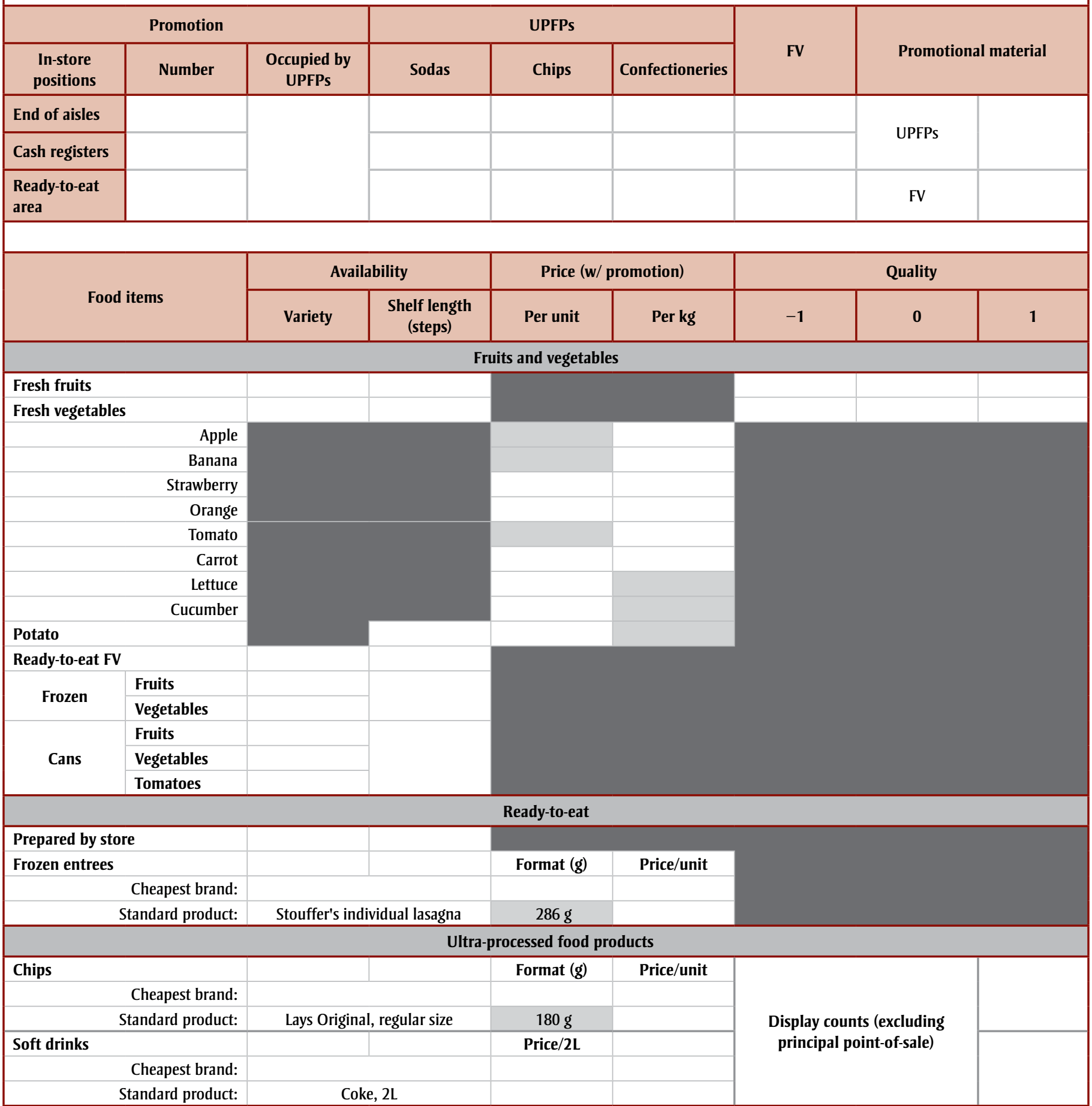

Abbreviations: FV, fruits and vegetables; MEAC-S, Mesure de l'environnement alimentaire du consommateur dans les supermarchés; UPFP, ultra-processed food product; $w /$, without. 
FIGURE 2

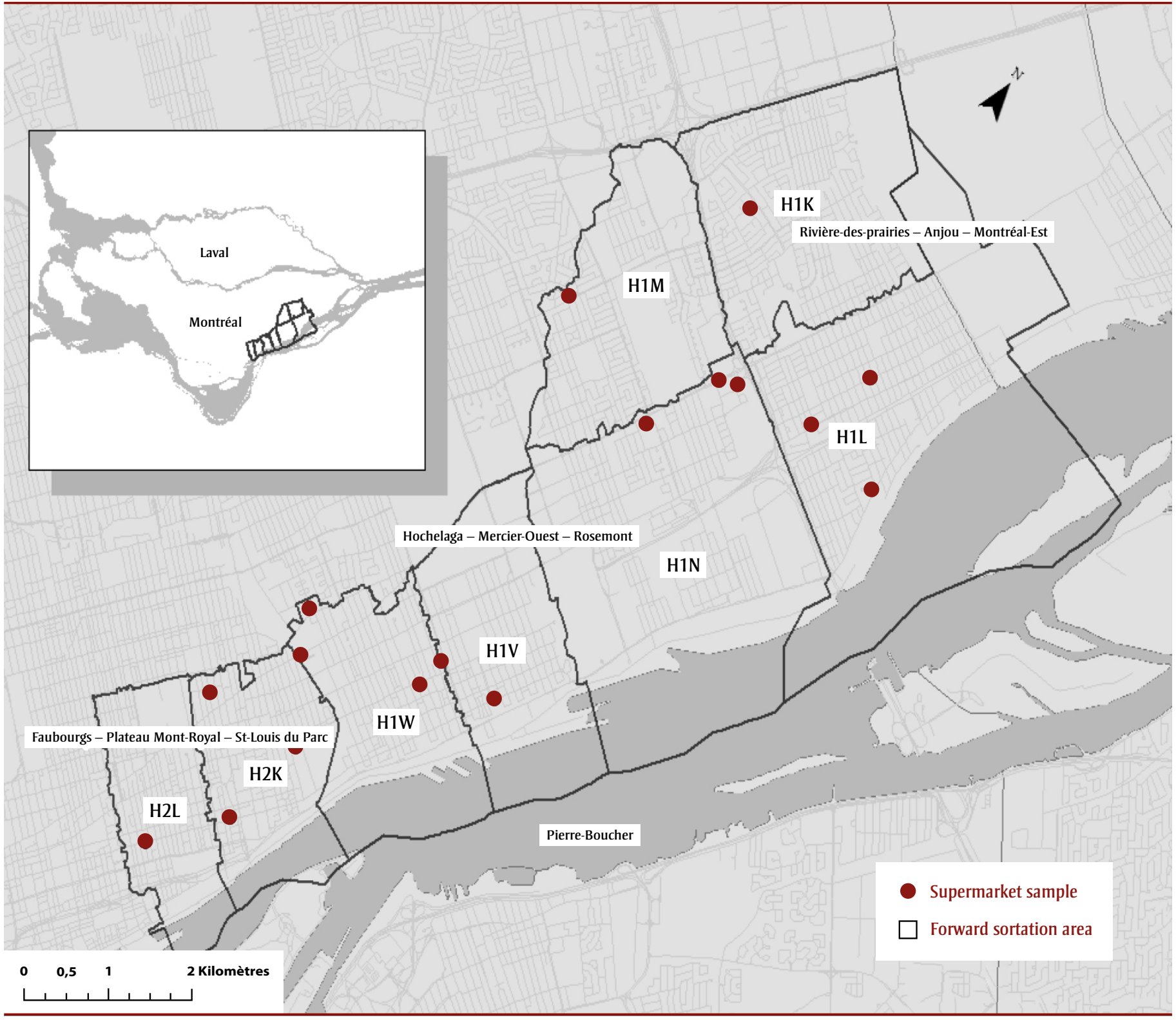

TABLE 1

Interrater and test-retest reliability for consumer food environment indicators included in the MEAC-S

\begin{tabular}{lcc}
\multicolumn{1}{c}{ Indicators } & \multicolumn{2}{c}{ ICC } \\
\cline { 2 - 3 } & Interrater & Test-retest \\
\hline Variety & 0.888 & 0.876 \\
Shelf length & 0.908 & 0.894 \\
Display counts & 0.951 & 0.431 \\
Quality & 0.968 & 0.968 \\
Price & 0.883 & NV \\
Strategic in-store positioning & 0.845 & 0.529 \\
Mean ICC for all indicators & 0.894 & 0.607 \\
\hline
\end{tabular}

Abbreviations: ICC, Intra-class correlation coefficient; MEAC-S, Mesure de l'environnement alimentaire du consommateur dans les supermarchés; $\mathrm{NV}$, not valid.
Store size was positively associated with UPFPs variety, display counts and strategic in-store positioning and inversely associated with the price of soft drinks. It was also positively correlated to FV variety and display counts, though it should be noted that additional display counts for FV were present in only 8 supermarkets out of 17 , and that most of these display counts were for canned, not fresh FV.

\section{Discussion}

This study's first objective was to develop a tool to assess the consumer nutrition environment inside supermarkets in the province of Quebec. The MEAC-S is used to audit foods that are under- or overconsumed 
TABLE 2

Descriptive analysis of the consumer food environment inside supermarkets in four neighborhoods of Montréal, Canada, 2015

\begin{tabular}{|c|c|c|c|}
\hline \multicolumn{2}{|c|}{ Consumer food environment indicators } & \multicolumn{2}{|c|}{ Supermarkets $(\mathbf{N}=17)$} \\
\hline & & Mean & $(\min -\max )$ \\
\hline \multirow{7}{*}{ 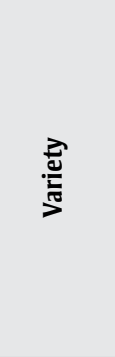 } & Fresh FV & 221.3 & $(149-319)$ \\
\hline & Total FV & 518.6 & $(361-757)$ \\
\hline & Ready-to-eat meals & 79.3 & $(0-187)$ \\
\hline & Frozen entrees & 134.5 & $(41-209)$ \\
\hline & Chips & 235.7 & $(123-338)$ \\
\hline & Soft drinks & 41.7 & $(27-50)$ \\
\hline & Ratio (FV/UPFPs) & 1.28 & $(0.89-1.48)$ \\
\hline \multirow{8}{*}{ 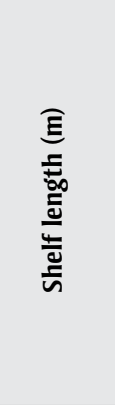 } & Fresh FV & 89.1 & $(18.2-166.4)$ \\
\hline & Total FV & 123.0 & $(34.8-223.4)$ \\
\hline & Ready-to-eat meals & 11.2 & $(0.0-29.7)$ \\
\hline & Frozen entrees & 46.4 & $(18.6-91.5)$ \\
\hline & Chips & 39.6 & $(14.2-82.0)$ \\
\hline & Soft drinks & 26.8 & $(9.5-70.9)$ \\
\hline & Ratio (FV/UPFPs) & 1.2 & $(0.64-2.34)$ \\
\hline & Total measured shelf length & 247.0 & $(88.4-455.3)$ \\
\hline \multirow{2}{*}{ 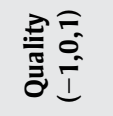 } & $\mathrm{F}$ & 0.8 & $(-0.5$ to 1.0$)$ \\
\hline & $\mathrm{V}$ & 0.9 & $(0.0-1.0)$ \\
\hline \multirow{8}{*}{ 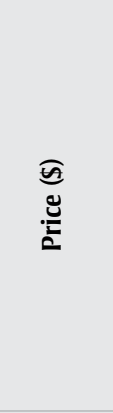 } & $\mathrm{F}$ (per portion) & 0.70 & $(0.43-1.22)$ \\
\hline & $\mathrm{V}$ (per portion) & 0.33 & $(0.22-0.53)$ \\
\hline & Frozen entrees, HB (per $100 \mathrm{~g}$ ) & 0.72 & $(0.47-0.93)$ \\
\hline & Stouffer's lasagna (per $100 \mathrm{~g}$ ) & 1.41 & $(1.39-1.57)$ \\
\hline & Chips, HB (per $100 \mathrm{~g}$ ) & 0.99 & $(0.74-1.25)$ \\
\hline & Lay's (per $100 \mathrm{~g}$ ) & 1.63 & $(1.23-1.99)$ \\
\hline & Soft drinks, HB (per 2 L) & 1.32 & $(1.00-1.99)$ \\
\hline & Coke (per $2 \mathrm{~L}$ ) & 2.38 & $(1.67-2.79)$ \\
\hline \multirow{3}{*}{ 蒿䓂 } & FV & 0.7 & $(0-3)$ \\
\hline & Chips & 9.9 & $(4-18)$ \\
\hline & Soft drinks & 5.5 & $(2-10)$ \\
\hline \multirow{4}{*}{ 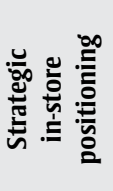 } & FV & 0.5 & $(0-2)$ \\
\hline & Chips & 6.9 & $(3-13)$ \\
\hline & Soft drinks & 5.7 & $(2-9)$ \\
\hline & Confectioneries & 10.7 & $(3-17)$ \\
\hline
\end{tabular}

Abbreviations: F, fruits; FV, fruits and vegetables; HB, house brand; UPFP, ultra-processed food product; V, vegetables.

Notes: "Strategic in-store positions" are the ends of aisles, areas near cash registers, and ready-to-eat displays.

"Total measured shelf length" is a proxy measure for store size.

in Quebec, using eight indicators that reflect the consumer food environment in stores.

Overall data suggest variability among supermarkets, particularly regarding shelf length measurements and price of FV. The price of FV varied more than twofold between supermarkets. This can result in a difference of over $\$ 30.00$ per week for a family of four, depending on their choice of supermarket, a considerable amount for low-income families living in the surveyed neighbourhoods.
Many studies have suggested that neighbourhood socioeconomic status (SES) is associated with FV and snack foods availability inside food retailers, ${ }^{46,47}$ thus mediating the relationship between individual SES and diet quality. ${ }^{33}$ However, the available data on SES in our study area do not match our geographic breakdown, thus restricting our ability to analyze the consumer food environment in the different FSAs with respect to their SES. Future studies should consider using geographic boundaries allowing for adequate integration of SES information.

Our results also showed that in this sample, almost $30 \%$ of the 17 supermarkets had a shelf length ratio below 1.0, indicating prominence of UPFPs in these stores. The limited number of UPFPs included in the MEAC-S likely underestimates this percentage.

Moreover, our data suggest that larger stores have more display counts and instore positioning of UPFPs than do smaller ones, a relationship that is not observed for FV. This result is consistent with previous research showing that unhealthy food item promotion seems to be related to store size, whereas FV are found less frequently and in less prominent spaces, regardless of store size. ${ }^{40}$ A study conducted in Montréal by Blanchard also suggested that shelf space of snack foods is more extensible than shelf space of $\mathrm{FV}^{46}$

Most studies on community food environment categorize supermarkets as healthy stores. $^{48}$ While it has been shown that they usually do have a greater availability of healthy foods at lower prices when compared to other types of stores, ${ }^{33,49}$ they also offer more UPFPs at lower prices ${ }^{19,50}$ and their in-store content may vary greatly among supermarkets. ${ }^{20,29}$ This study confirms these results and suggests that supermarkets cannot be uniformly considered healthy stores. Many researchers are urging their colleagues to explore the consumer nutrition environment further and revise their categorization of stores as healthy or unhealthy. ${ }^{23,29,32,51}$

In contrast to availability and price, produce quality did not vary among stores. This is probably due to the highest quality standard to which chain supermarkets adhere. In this context, the assessment of produce quality might be more valuable when comparing the food environment 
TABLE 3

Spearman correlations between prominence and promotion indicators and price of ultra-processed food products

\begin{tabular}{|c|c|c|c|c|c|c|c|c|c|c|}
\hline Price & $\begin{array}{c}\text { Display } \\
\text { counts: chips }\end{array}$ & $\begin{array}{c}\text { Display } \\
\text { counts: soft } \\
\text { drinks }\end{array}$ & $\begin{array}{l}\text { Display } \\
\text { counts: } \\
\text { UPFPs }\end{array}$ & $\begin{array}{c}\text { Strategic } \\
\text { in-store } \\
\text { positioning: } \\
\text { chips }\end{array}$ & $\begin{array}{l}\text { Strategic } \\
\text { in-store } \\
\text { positioning: } \\
\text { soft drinks }\end{array}$ & $\begin{array}{l}\text { Strategic } \\
\text { in-store } \\
\text { positioning: } \\
\text { UPFPs }\end{array}$ & $\begin{array}{c}\text { Shelf length: } \\
\text { chips }\end{array}$ & $\begin{array}{l}\text { Shelf length: } \\
\text { soft drinks }\end{array}$ & $\begin{array}{c}\text { Shelf length: } \\
\text { ratio }\end{array}$ & $\begin{array}{c}\text { Variety: soft } \\
\text { drinks }\end{array}$ \\
\hline \multirow{2}{*}{ Chips (HB) } & -0.690 & \multirow{2}{*}{ NS } & -0.674 & -0.641 & \multirow{2}{*}{ NS } & \multirow{2}{*}{ NS } & -0.521 & -0.489 & 0.661 & \multirow{2}{*}{ NS } \\
\hline & $p=0.002$ & & & & & & $p=0.032$ & $p=0.046$ & $p=0.004$ & \\
\hline \multirow{2}{*}{$\begin{array}{l}\text { Soft drinks } \\
\text { (Coke) }\end{array}$} & -0.808 & -0.653 & -0.865 & -0.842 & -0.533 & -0.834 & -0.804 & -0.767 & 0.695 & -0.667 \\
\hline & $p<0.001$ & $p=0.004$ & $p<0.001$ & $p<0.001$ & $p=0.028$ & $p<0.001$ & $p<0.001$ & $p<0.001$ & $p=0.002$ & $p=0.003$ \\
\hline
\end{tabular}

Abbreviations: HB, house brand; NS, nonsignificant; UPFPs, ultra-processed food products.

Note: "Shelf length: ratio" is the ratio of FV shelf length to UPFPs shelf length.

inside different types of stores. It is also worth mentioning that in most supermarkets we visited, the produce section was located at the store entrance. These choices are likely not arbitrary and may reflect the marketing practices of store owners. A US study reports that consumers who choose to purchase food perceived as healthy, such as fresh FV, are more likely to choose to purchase highenergy-density and ultra-processed products later in their store visit. ${ }^{52}$

This study also found an inverse relationship between the price, promotion and prominence of UPFPs, but not of FV. Price, promotion and prominence are known to have a central influence on food purchasing behaviour. Marketing research suggests that increasing the shelf space, lowering the price and displaying products at the end of aisles or near cash registers all lead to increasing sales of these products. $^{14,37-40}$

Notably, UPFPs were promoted in this way in all stores included in the study, which was not the case for FV. Strategic in-store positioning of unhealthy items not only increases the purchase of these items in percentage of total sales, but also reduces the purchase of $\mathrm{FV}^{40}$ Considering the influence of promotion and prominence on sales, a promising strategy to improve the consumer nutrition environment without compromising store profitability could be to encourage store managers, through financial incentives or regulations, to also apply this marketing mix to FV. ${ }^{37,39}$

\section{Strengths and limitations}

This study has many strengths and limitations. The MEAC-S was validated for interrater reliability with satisfactory ICC coefficients for all indicators, suggesting excellent agreement between raters. The ICC coefficients for test-retest reliability were somewhat less satisfactory. The production of FV being closely linked to climate and temperature, seasonal changes influence the in-store availability and price of produce, which could explain the lower ICC scores. Moreover, display counts and in-store positioning of food products may not be constant over time. This might be linked with in-store positioning of food products related to seasonal particularities or holidays. To limit the influence of seasonality on ICC scores, test-retest reliability of the MEAC-S should be evaluated again using a shorter timeframe. Precautions should also be taken when using the MEAC-S to assess the food environment quality over time or when comparing stores or neighbourhoods. To maximize comparability, the assessment should be done within the same season.

Another strength of this study is the indicators and measurements used. The MEAC-S tool includes every variety of each of the food categories surveyed. While including a larger variety can be time-consuming, it could allow for a more sensitive classification of food stores with regards to FV and food products availability. (For example, a study conducted in Montréal failed to detect differences between stores by SES area while using the NEMS-S checklist for fresh FV, but detected a significant difference when using a homemade checklist of 137 fresh $\mathrm{FV}^{46}$ )

Additionally, the MEAC-S integrates measures of food prominence and promotion, such as additional display counts and strategic in-store positioning, which were found to be closely related to purchase

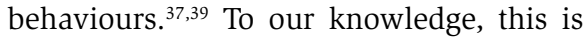
the first study to integrate both of these measurements in a food store survey. The MEAC-S also combines both absolute and relative indicators, which better illustrates the simultaneous exposure of consumers

TABLE 4

Spearman correlations between store size and indicators of the consumer food environment inside supermarkets of four neighborhoods of Montréal, Canada

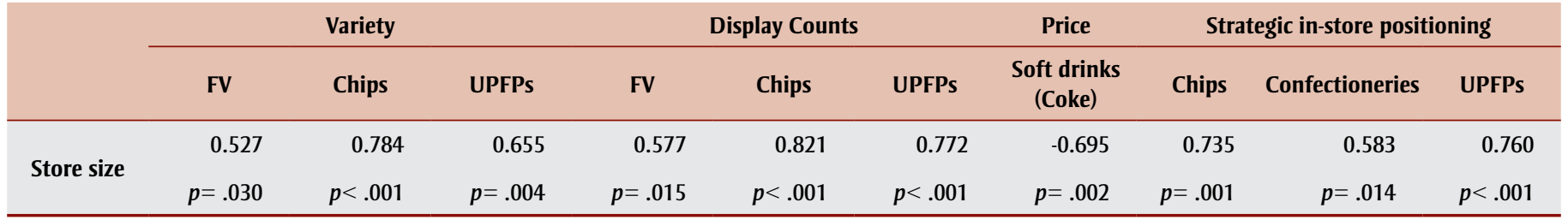

Abbreviations: FV, fruits and vegetables; UPFPs, ultra-processed food products. 
to both healthy and unhealthy food items. ${ }^{29,48,49}$

Finally, unlike the method proposed by other audit tools, MEAC-S indicators were not aggregated into a global quality score per supermarket. Results from different indicators did not converge and were sometimes in opposition regarding the quality of the food environment inside supermarkets (e.g. price per portion of vegetable positively correlated with $\mathrm{FV}$ prominence). Aggregation of these contrasting results would not give a complete and accurate picture of the situation and would possibly underestimate the importance of one or many indicators in relation with consumer's purchase behaviours or health outcomes. Moreover, all indicators of the consumer food environment may not be linked with dietary outcomes or weight in the same way and in every population subgroup..$^{51}$ The MEAC-S, by generating data for multiple indicators, allows for analysis between each component of the consumer food environment and dietary or health outcomes.

The main limitation of the MEAC-S is the inclusion of only a limited number of food products for assessment. This limitation was intended to ensure the tool was convenient and easy to use, particularly for public health practitioners that lack both time and human resources mostly due to budget constraints. The exclusion of UPFPs other than chips, soft drinks, frozen entrees and confectioneries likely underestimates the prominence of this category of products in our food environment. Furthermore, the MEAC-S does not provide information regarding healthy options within these food groups or for other available food categories, such as grains and proteins.

Another important limitation of this study is the exclusion of food stores other than supermarkets. There was a wide variety of other types of food stores in the study area, such as small grocery stores and produce stands. In Quebec, these types of stores accounted for $12.2 \%$ of food purchases in 2013 , while $55.2 \%$ of food were purchased in supermarkets. ${ }^{53}$ Therefore, excluding other types of stores may misrepresent the consumer food environment of neighbourhoods residents. ${ }^{29}$ However, most consumers tend to choose supermarkets as their primary food store and visit other types of stores for smaller, complementary purchases between their main food shopping trips. ${ }^{17,33}$ The inclusion of every supermarket within the four neighbourhoods thus probably depicts at least part of the food environment to which most of the residents are exposed.

In order to more accurately reflect financial accessibility to food items, promotion prices were excluded from the observations, despite their known influence on purchase behaviours. ${ }^{54}$ In addition to display counts and strategic in-store positioning, further studies could also assess the frequency of price promotions per food category. Other limitations include the small sample of supermarkets and the urban, low-to-medium income setting in which the study was conducted, limiting the ability to generalize results to rural or higher-income areas.

\section{Conclusion}

To our knowledge, the MEAC-S is the first tool developed to assess the consumer food environment using such a broad set of measures, integrating availability and price, but also prominence and promotion indicators. Results illustrate the prominence and promotion of UPFPs over FV in the neighbourhoods surveyed and underscores the necessity to adequately picture the consumer food environment to which consumers are exposed, breaking with the dichotomous classification of stores as healthy or unhealthy. The MEAC-S could be used to reliably characterize and monitor the consumer food environment inside supermarkets, providing much-needed data to inform interventions and policies targeting the food environment to ultimately improve eating habits at the population level.

\section{Acknowledgements}

This project was in part supported by a Canada Graduate Scholarship-Master's Program from the Canadian Institutes of Health Research (CIHR).

\section{References}

1. Statistics Canada. CANSIM database: Table 105-0507: Measured adult body mass index (BMI), by age group and sex, household population aged 18 and over excluding pregnant females, Canada (excluding territories) [Internet]. Ottawa (ON): Statistics Canada; 2016 [cited 2016 Oct 28]. Available from: http://www5.statcan.gc.ca/cansim /a26?lang $=$ eng\&id $=1050507$
2. Tran BX, Nair AV, Kuhle S, Ohinmaa A, Veugelers PJ. Cost analyses of obesity in Canada: scope, quality, and implications. Cost Eff Resour Alloc [Internet]. 2013 [cited 2016 Oct 28]; 11(1):3. Available from: http://dx.doi .org/10.1186/1478-7547-11-3

3. Blouin C, Hamel D, Vandal N, Jen Y, Lo E, Martel S. Les conséquences économiques associées à l'obésité et l'embonpoint au Québec: les coûts liés à la consommation de médicaments et à l'invalidité - mise à jour 2016. Québec (QC): Institut national de santé publique Québec (INSPQ); 2015 Oct. 25 p. (Fardeau du poids corporel). [Report No.: 2035].

4. WHO-FAO Expert Consultation, editor. Diet, nutrition, and the prevention of chronic diseases: report of a WHO-FAO Expert Consultation. Geneva $(\mathrm{CH})$ : World Health Organization; 2003. 149 p. (WHO technical report series, No. 916).

5. Blanchet C, Rochette L, Plante C, Institut national de santé publique du Québec (INSPQ), Direction recherche formation et développement. La consommation alimentaire et les apports nutritionnels des adultes québécois [Internet]. Montréal (QC): INSPQ; 2009 [cited 2016 Oct 28]. Available from: http://public.eblib.com/choice /publicfullrecord.aspx?p = 3265815

6. Moubarac J-C, Batal M. La consommation d'aliments transformés et la qualité de l'alimentation au Québec [Internet]. Montréal (QC): TRANSNUT; 2016 Mar. 22 p. Available from: http://www.rccq.org/wp-content /uploads/Qu \% C3 \% A9bec-MSSS -consommation-daliments-ultra -transform \% C3 \% A9s-et-qualit \% C3\% A9-de-lalimentation_Moubarac -et-Batal-2016.pdf

7. Glanz K, Sallis JF, Saelens BE, Frank LD. Healthy nutrition environments: concepts and measures. Am J Health Promot. 2005;19(5):330-3, ii.

8. Caspi CE, Kawachi I, Subramanian SV, Adamkiewicz G, Sorensen G. The relationship between diet and perceived and objective access to supermarkets among low-income housing residents. Soc Sci Med. 2012;75(7): 1254-62. 
9. Izumi BT, Zenk SN, Schulz AJ, Mentz GB, Wilson C. Associations between neighborhood availability and individual consumption of dark-green and orange vegetables among ethnically diverse adults in Detroit. J Am Diet Assoc. 2011;111(2):274-9.

10. Morland K, Wing S, Diez Roux A. The contextual effect of the local food environment on residents' diets: the Atherosclerosis Risk in Communities study. Am J Public Health. 2002; 92(11):1761-7.

11. Rose D, Richards R. Food store access and household fruit and vegetable use among participants in the US Food Stamp Program. Public Health Nutr. 2004;7(8):1081-8.

12. Zenk SN, Lachance LL, Schulz AJ, Mentz G, Kannan S, Ridella W. Neighborhood retail food environment and fruit and vegetable intake in a multiethnic urban population. Am J Health Promot. 2009;23(4): 255-64.

13. Aggarwal A, Cook AJ, Jiao J, et al. Access to supermarkets and fruit and vegetable consumption. Am J Public Health. 2014;104(5):917-23.

14. Cheadle A, Psaty BM, Curry S, et al. Community-level comparisons between the grocery store environment and individual dietary practices. Prev Med. 1991;20(2):250-61.

15. Moore LV, Diez Roux AV, Nettleton JA, Jacobs DR. Associations of the local food environment with diet quality-a comparison of assessments based on surveys and geographic information systems: the multi-ethnic study of atherosclerosis. Am J Epidemiol. 2008;167(8):917-24.

16. Franco M, Diez-Roux AV, Nettleton JA, et al. Availability of healthy foods and dietary patterns: the Multi-Ethnic Study of Atherosclerosis. Am J Clin Nutr. 2009;89(3):897-904.

17. Gustafson A, Christian JW, Lewis S, Moore K, Jilcott S. Food venue choice, consumer food environment, but not food venue availability within daily travel patterns are associated with dietary intake among adults, Lexington Kentucky 2011. Nutr J [Internet]. 2013 [cited 2016 Oct 28];12:17. Available from: http://dx.doi.org/10.1186/1475 $-2891-12-17$
18. Gustafson A, Lewis S, Perkins S, Wilson C, Buckner E, Vail A. Neighbourhood and consumer food environment is associated with dietary intake among Supplemental Nutrition Assistance Program (SNAP) participants in Fayette County, Kentucky. Public Health Nutr. 2013; 16(7):1229-37.

19. Rose D, Hutchinson PL, Bodor JN, et al. Neighborhood food environments and body mass index: the importance of in-store contents. Am J Prev Med. 2009;37(3):214-9.

20. Chaix B, Bean K, Daniel $M$, et al. Associations of supermarket characteristics with weight status and body fat: a multilevel analysis of individuals within supermarkets (RECORD Study). PLOS ONE [Internet]. 2012 [cited 2016 Oct 26];7(4):e32908. Available from: https://doi.org/10.1371 /journal.pone.0032908

21. Morland K, Diez Roux AV, Wing S. Supermarkets, other food stores, and obesity: the Atherosclerosis Risk in Communities study. Am J Prev Med. 2006;30(4):333-9.

22. Spence JC, Cutumisu N, Edwards J, Raine KD, Smoyer-Tomic K. Relation between local food environments and obesity among adults. BMC Public Health [Internet]. 2009 [cited 2016 Oct 28];9:192. Available from: https://doi.org/10.1186/1471-2458 $-9-192$

23. Le $H$, Engler-Stringer $\mathrm{R}$, Muhajarine $\mathrm{N}$. Walkable home neighbourhood food environment and children's overweight and obesity: proximity, density or price? Can J Public Health. 2016;107 (Suppl 1):eS42-eS47.

24. Minaker LM, Raine KD, Wild TC, Nykiforuk CIJ, Thompson ME, Frank LD. Objective food environments and health outcomes. Am J Prev Med. 2013;45(3):289-96.

25. Powell LM, Auld MC, Chaloupka FJ, O'Malley PM, Johnston LD. Associations between access to food stores and adolescent body mass index. Am J Prev Med. 2007;33(4 Suppl):S301-S307.

26. Moubarac J-C, Batal M, Martins AP, et al. Processed and ultra-processed food products: consumption trends in Canada from 1938 to 2011. Can J Diet Pract Res. 2014;75(1):15-21.
27. Myers CA, Slack T, Martin CK, Broyles ST, Heymsfield SB. Change in obesity prevalence across the United States is influenced by recreational and healthcare contexts, food environments, and hispanic populations. PLOS ONE [Internet]. 2016 Feb 5 [cited 2016 Oct 28];11(2):e0148394. Available from: https://doi.org/10 .1371/journal.pone.0148394

28. Swinburn BA, Sacks G, Hall KD, McPherson K, Finegood DT, Moodie ML, et al. The global obesity pandemic: shaped by global drivers and local environments. Lancet. 2011; 378(9793):804-14.

29. Lucan SC. Concerning limitations of food-environment research: a narrative review and commentary framed around obesity and diet-related diseases in youth. J Acad Nutr Diet. 2015;115(2):205-12.

30. Minaker LM, Shuh A, Olstad DL, Engler-Stringer R, Black JL, Mah CL. Retail food environments research in Canada: a scoping review. Can J Public Health. 2016;107(Suppl 1):eS4eS13.

31. Odoms-Young A, Singleton CR, Springfield S, McNabb L, Thompson T. Retail environments as a venue for obesity prevention. Curr Obes Rep. 2016;5(2):184-91.

32. Caspi CE, Sorensen G, Subramanian SV, Kawachi I. The local food environment and diet: a systematic review. Health Place. 2012;18(5): 1172-87.

33. Cannuscio CC, Tappe K, Hillier A, Buttenheim A, Karpyn A, Glanz K. Urban food environments and residents' shopping behaviors. Am J Prev Med. 2013;45(5):606-14.

34. Glanz K, Johnson L, Yaroch AL, Phillips M, Ayala GX, Davis EL. Measures of retail food store environments and sales: review and implications for healthy eating initiatives. J Nutr Educ Behav. 2016;48(4):280288.e1.

35. Glanz K, Sallis JF, Saelens BE, Frank LD. Nutrition Environment Measures Survey in Stores (NEMS-S): development and evaluation. Am J Prev Med. 2007;32(4):282-9. 
36. Carlson A, Lino M, Juan W, Hanson K, Basiotis PP. Thrifty Food Plan, 2006. Washington (DC): US Department of Agriculture, Center for Nutrition Policy and Promotion; 2007 [Report No.: CNPP-19].

37. Curhan RC. The effects of merchandising and temporary promotional activities on the sales of fresh fruits and vegetables in supermarkets. J Mark Res. 1974;11(3):286-94.

38. Wilkinson JB, Mason JB, Paksoy CH. Assessing the impact of short-term supermarket strategy variables. J Mark Res. 1982;19(1):72-86.

39. Foster GD, Karpyn A, Wojtanowski AC, Davis E, Weiss S, Brensinger C, et al. Placement and promotion strategies to increase sales of healthier products in supermarkets in low-income, ethnically diverse neighborhoods: a randomized controlled trial. Am J Clin Nutr. 2014;99(6):1359-68.

40. Kerr J, Sallis JF, Bromby E, Glanz K. Assessing reliability and validity of the GroPromo audit tool for evaluation of grocery store marketing and promotional environments. J Nutr Educ Behav. 2012;44(6):597-603.

41. Monteiro C, Cannon G, Levy RB, Claro RM, Moubarac J-C. The food system. Ultra-processing. The big issue for nutrition, disease, health, well-being. [Commentary]. World Nutr. 2012;3(12): 527-569.

42. Private database of $\mathrm{M}-\mathrm{C}$ Paquette (Université de Montréal, Montréal, QC), accessed September 2015 to December 2016.

43. Bertrand L, Thérien F, Agence de la santé et des services sociaux de Montréal (Québec), Direction de santé publique. Les disparités dans l'accès à des aliments santé à Montréal : une étude géomatique [Internet]. Montréal (QC): Direction de santé publique Montréal, Agence de la santé et des services sociaux de Montréal; 2006 [cited 2016 Oct 28]. Available from: https://publications.santemontreal.qc .ca/uploads/tx_asssmpublications /2-89494-516-7.pdf
44. Paquette M-C, Bergeron P. Cadre de référence des indicateurs d'achats pour caractériser l'alimentation et l'environnement alimentaire au Québec [Internet]. Montréal (QC): Institut national de santé publique du Québec; 2016 Oct [cited 2016 Oct 28]. Available from: https://www.inspq.qc.ca /publications/2180

45. Fleiss JL, Levin B, Paik MC. The measurement of interrater agreement. In: Statistical methods for rates and proportions [Internet]. Hoboken (NJ): John Wiley \& Sons; 2003 [cited 2016 Oct 28]. p. 598-626. Available from: http://onlinelibrary.wiley.com/doi /10.1002/0471445428.ch18/summary

46. Blanchard L. Disparities in the availability of fruit, vegetables and snack foods by neighborhood socioeconomic status in supermarkets and grocery stores in Montréal, Canada [master's thesis]. Copenhagen (DK): Copenhagen University \& University of Sheffield; 2012. 77 p.

47. Zenk SN, Powell LM, Rimkus L, et al. Relative and absolute availability of healthier food and beverage alternatives across communities in the United States. Am J Public Health. 2014;104(11):2170-8.

48. Cobb LK, Appel LJ, Franco M, JonesSmith JC, Nur A, Anderson CAM. The relationship of the local food environment with obesity: a systematic review of methods, study quality, and results. Obes (Silver Spring). 2015;23(7):1331-44.

49. Farley TA, Rice J, Bodor JN, Cohen DA, Bluthenthal RN, Rose D. Measuring the food environment: shelf space of fruits, vegetables, and snack foods in stores. J Urban Health. 2009;86(5):672-82.

50. Miller C, Bodor JN, Rose D. Measuring the food environment: a systematic technique for characterizing food stores using display counts. $\mathrm{J}$ Environ Public Health [Internet]. 2012 Jun 4;2012:e707860. Available from: http://dx.doi.org/10.1155/2012 /707860

51. Gustafson A, Hankins S, Jilcott S Measures of the consumer food store environment: a systematic review of the evidence 2000-2011. J Community Health. 2012;37(4):897-911.
52. Hui SK, Bradlow ET, Fader PS. Testing behavioral hypotheses using an integrated model of grocery store shopping path and purchase behavior. J Consum Res. 2009;36(3):478-93.

53. Labrecque J, Dupuis R, Doyon M, Dufour J-C. Approvisionnement du marché alimentaire québécois : des stratégies gagnantes [Internet]. Montréal (QC): CIRANO; 2016 [cited 2016 Oct 28]. 130 p. [Report No.: 2016RP-06.] Available from: https://www.cirano .qc.ca/files/publications/2016RP-06 .pdf

54. Nakamura R, Suhrcke M, Jebb SA, Pechey R, Almiron-Roig E, Marteau TM. Price promotions on healthier compared with less healthy foods: a hierarchical regression analysis of the impact on sales and social patterning of responses to promotions in Great Britain. Am J Clin Nutr. 2015 Mar 1;ajcn.094227. 